\title{
Caylus y el Tirant: un anticuario universal y una novela
}

\section{Caylus and Tirant: the Universal Antiquarian and the Novel}

\author{
Huayta Montoya Uriarte \\ (Universitat de Barcelona \\ Programa de Máster en Gestión de Patrimonio Cultural y Museología \\ / El Colegio de México, Programa de Doctorado en Historia)
}

\section{RESUM}

En este artículo estudiamos la figura de Anne-Claude-Philippe de Tubières de Grimoard de Pestels de Lévis, Conde de Caylus (París, 1692-1765), en su interés por la literatura y las antigüedades de Valencia. Primero presentamos una breve semblanza biográfica del personaje; luego revisamos su participación en la primera edición y traducción francesa del Tirant lo Blanc, y finalmente, lo recordamos difundiendo los hallazgos arqueológicos de Sagunto. Ponemos al personaje en relación con Nicolas Fréret y Jean-Baptiste Souchay, y con Gregorio Mayans y Manuel Martí. Además, con su tío, el Duque de Caylus, gobernador de Valencia. Las relaciones quedan establecidas a los dos lados de los Pirineos.

\section{Paraules Clau}

Tirant lo Blanc, Duque de Caylus, Nicolas Fréret, Jean-Baptiste Souchay, Gregorio Mayans, Manuel Martí, traducción español-francés.

\section{Abstract}

In this article we explore the personality of Anne-Claude-Philippe de Tubières de Grimoard de Pestels de Lévis, Count of Caylus (Paris, 1692-1765), and we focus in his interest in Valencian literature and antiques. First, we present a short biographical sketch of the author; then we review his participation in the first French edition and translation of Tirant lo Blanc, and finally, we remember his interest in spreading archaeological finds of Sagunto. As a whole, we put him in contact with Nicolas Fréret and Jean-Baptiste Souchay, and with Gregorio Mayans and Manuel Martí. In addition, with his uncle, the Duke of Caylus, governor of Valencia. Relations are established on both sides of the Pyrenees.

\section{KEYWORDS}

Tirant lo Blanc, Duke of Caylus, Nicolas Fréret, Jean-Baptiste Souchay, Gregorio Mayans, Manuel Martí, SpanishFrench translation. 
Rebut: $20 / 05 / 2021$

Acceptat: 30/09/2021

Entre los especialistas y conocedores de la novela de caballerías Tirant lo Blanc, el nombre del Conde de Caylus se identifica con el patrocinador-promotor y traductor de la primera edición francesa que se conoce. En este trabajo pretendemos contribuir al conocimiento de este personaje, precisando su relación con la cultura valenciana, atendiendo básicamente a su interés por la citada novela y las antigüedades del país. ${ }^{1}$ Centrados en el siglo XVIII, en el marco de la historia de la cultura de la España de la Ilustración, nos interesa destacar los puntos de contacto, las relaciones y los intercambios que se establecieron sobre estos temas a los dos lados de los Pirineos.

Comenzaremos por presentar una muy breve semblanza biográfica del Conde de Caylus, en cuanto personaje multifacético que animó la vida artística y cultural del París de la primera mitad del siglo XVIII, dejando asentadas las razones por las que se distinguió en su tiempo como un anticuario con intereses universales. Después, una vez delineado el contexto y respetando el orden de los acontecimientos, nos ocupamos en primer lugar de la edición del Tirant le Blanc que patrocinó, y del papel que desempeñaron sus dos eventuales colaboradores, Fréret y Souchay. La mención al segundo, surge en el entorno intelectual y erudito de Gregorio Mayans y Siscar, figura central de las letras valencianas y contemporáneo del Conde de Caylus; aunque no pueda quedar probado un contacto directo entre ambas personalidades al tiempo de la publicación de la traducción francesa del Tirant, hay sintonía en el interés compartido por las literaturas hispánicas, y singularmente por Cervantes. En la segunda parte del artículo, en materia de antigüedades, sí que podemos demostrar la relación directa de Caylus con Mayans. Además, ubicamos a un tío paterno del Conde, participando de este mismo entusiasmo.

El interés de Caylus por el Tirant antecede y prefigura su conocimiento de las antigüedades valencianas. Ocurre en un tiempo en que los amantes de la literatura estaban lejos de disponer de datos básicos sobre esta novela. No se tenía idea que la obra original había sido escrita en catalán y publicada por primera vez en Valencia (1490) y así reimpresa después en Barcelona (1497), y que luego llegaron las traducciones castellana (Valladolid, 1511) e italiana (Venecia, 1538). Tampoco se conocía que el autor era Joanot Martorell (Valencia, 1410-1465) y que el último poseedor del manuscrito había sido Martí Joan de Galba (m. 1490). Menos aún, que la primera parte del Tirant, con la historia de Guillem de Varoic, se inspiraba en una novela caballeresca inglesa del siglo XIII, Guy of Warwick. Todo esto se ha ido conociendo sumando esfuerzos varios, y no parece haber dudas sobre el hecho de que fue en el siglo XVIII cuando se comenzó a asentar sobre sólidos cimientos la historia crítica de la obra. Sin duda la edición de Caylus forma parte de ella.

\section{Las etapas destacadas de la vida de Caylus}

Anne-Claude-Philippe de Tubières-Grimoard de Pestels de Lévis, Conde de Caylus (París, 1692-1765) — a quien conocemos popularmente como Caylus - fue un noble parisino muy rico, cuya vida transcurrió dedicado a sus quehaceres artísticos e intelectuales. ${ }^{2}$ No ejerció cargos polí-

1. La base de este artículo está en nuestro trabajo (Montoya, 2020), dedicado a la faceta anticuaria de Caylus y a sus relaciones con España.

2. Remitimos, para citas y bibliografía sobre su biografía, a Montoya (2020). Añadimos la referencia al trabajo de Gougeaud-Arnaudeau (2010), con especial énfasis en lo artístico. 
ticos ni administrativos de ningún tipo, y no contrajo matrimonio ni tuvo hijos. Su firma y nombre preside, un gran número de obras de contenido temático bastante diverso que Peeters (2004) organiza en materias de arte, antigüedades y letras. Del conjunto, sobresale por su extensión e importancia el célebre Recueil d'Antiquités égyptiennes, étrusques, grecques, romaines et gauloises (París, 1752-1767), publicado en siete volúmenes (el último, póstumo), que recoge el contenido de sus colecciones particulares de antigüedades y la propuesta de una novedosa metodología para estudiar las fuentes materiales del pasado.

Caylus se crio y educó en la corte de Versalles, al amparo de una madre muy conocida y de gustos muy refinados. ${ }^{3}$ Se incorporó muy joven a la carrera de las armas, y de este modo anduvo por Cataluña, Mallorca y Malta. A los 22 años, desistió de la milicia, emprendió el «Grand Tour» por Europa y en la península itálica quedó marcado por las bellas artes y las antigüedades, De regreso a Francia, se estableció en París, ciudad en la que residió hasta el final de sus días.

Se inicia entonces, hacia 1720, la etapa esencialmente artística de su vida. Caylus frecuenta los gabinetes y círculos locales de pintura, escultura, dibujo y grabados (que él mismo ejecuta), y visita con regularidad las colecciones reales (estampas, monedas, medallas y antigüedades en general). Se incorpora en 1731 a la Academia Real de Pintura y Escultura, donde escribe biografías sobre pintores y escultores franceses, además de ensayos sobre temas artísticos varios. Disfruta igualmente componiendo literatura y teatro, y participa como actor en el llamado «teatro de sociedad» de la época. En su entusiasmo por las artes escénicas se le relaciona con la famosa actriz y escritora Jeanne Quinault, más conocida como Mlle. Quinault, y en el ámbito de los grandes salones que acogen a los intelectuales del momento, es habitual en el de Mme. Geoffrin, reconocida protectora de artistas y enciclopedistas. Caylus participó plenamente de la vida social y artística parisina de la época, y tuvo sus desencuentros con un «clan literario « que le era profundamente contrario; animado por el célebre enciclopedista Denis Diderot y por otros intelectuales como Jean-François Marmontel, les separaban sus opiniones diferenciadas sobre el arte moderno, pero también, mucha antipatía personal.

A partir de su ingreso en la Academia de Inscripciones y Bellas Letras (1742), la vida del Conde, según propia confesión, dio un gran giro y sus intereses se orientaron con prioridad hacia la antigüedad. Buscando conocer las técnicas del arte antiguo ( «los medios que usaban los antiguos para operar»), Caylus profundizó en el conocimiento y estudio de los objetos antiguos, y esta fue su ocupación preferente durante los últimos veinte años de su vida. De todo ello son buen testimonio las memorias que comunicó a la Academia, y muy especialmente su obra mayor.

Es la época de crecimiento y expansión de sus colecciones, pero Caylus no es un anticuario al uso, porque una vez estudiadas las piezas, las obsequia al monarca francés, o las regala e intercambia, para adquirir nuevas piezas que analizar. En un pasaje conocido de su correspondencia, Caylus le decía en 1758 a su proveedor en Italia:

Le ruego que recuerde siempre que no hago un gabinete, que no siendo la vanidad mi objeto, me importan poco las piezas de ostentación; sin embargo, los desechos (andrajos) de ágata, piedra, bronce, tierra, vidrio, que puedan servir en el modo que sea para encontrar un uso, o el pasaje de un autor, son objeto de mis deseos. Yo no hago un gabinete,

3. Fueron sus padres Jean-Anne de Tubières-Grimoard de Pestels \& de Levi Conde de Caylus (m. 1704), menino del Gran Delfín de Francia, y teniente general, y Marthe-Marguerite-Hyppolite Le Valois (m. 1729), hija de Philippe le Valois Marqués de Villette y de Mursay y de Marie-Anne-Hippolyte de Châteauneuf. Para mayor precisión sobre la genealogía de los Caylus hemos recurrido a Courcelles (1824). La madre de Caylus fue educada y protegida como una hija por su tía paterna, Madame de Maintenon, esposa secreta del rey Louis XIV. Véase Raunié (1881) y Leroy y Loyau (1998). 
hago un curso de antigüedad, y yo busco los usos, aquello que los prueba, los practica, los demuestra. ${ }^{4}$

Caylus eligió las «Advertencias» y los «Prefacios» de su obra mayor, el Recueil, para presentar las grandes líneas de su «método» de trabajo. ${ }^{5}$ Los objetos y sus fragmentos debían estudiarse por sí mismos, por la vía de la comparación y de la clasificación, más allá de su relación con los textos literarios. Atendiendo a las similitudes y diferencias en sus dimensiones, materias, técnicas, formas, decoraciones o dibujos, los materiales se podían organizar según los «gustos» reinantes. La propuesta era verdaderamente renovadora, una «ciencia universal de objetos» no limitada a las «bellas artes» y con proyección hasta la prehistoria. Caylus incorporó aquí los materiales que sus corresponsales le hicieron llegar; desde España, las antigüedades procedían de Valencia, Barcelona o Cádiz. El interés de Caylus alcanzó también lo americano precolombino.

La monumental obra de Caylus se asentaba sobre sólidos apoyos. El Conde reconoció una deuda de trabajo especial, en lo relativo al método, hacia Francesco Ficoroni (1664-1747), figura de referencia del anticuariado romano. En punto de erudición, su reconocimiento se dirigió hacia sus compañeros de la Academia de Inscripciones y Bellas Letras, con mención especial al abate Jean-Jacques Barthélemy (1716-1795), titular de las colecciones reales de antigüedades del rey de Francia. ${ }^{6}$

Además de ellos, sabemos que Caylus estableció una gran red de colaboradores para hacer posible el Recueil. ${ }^{7}$ Él mismo no practicaba excavaciones, pero tenía agentes en diferentes ciudades, dentro y fuera de Francia, para proporcionarle piezas e informaciones variadas, tal y como se puede leer en los reconocimientos puntuales de muchas de sus disertaciones. Caylus tenía, además, dibujantes y grabadores que trabajaron junto a él o para él en la ilustración de las más de 800 láminas del Recueil. A decir de uno de sus biógrafos menos conocidos, el ingeniero François Pasumot (1733-1804), Caylus no solo se procuraba de dibujos exactos de los monumentos que no se podían transportar; también encargaba examinar y copiar con fidelidad las inscripciones y los monumentos que le interesaban, y si lo consideraba necesario, mandaba hacer excavaciones. Junto a ello, Pasumot aseguraba que Caylus protegió, ayudó y socorrió durante toda su vida a quienes se aplicaban a las ciencias y a las artes, sacando de este modo de la obscuridad a numerosos talentos (Pasumot, 1813 [1766]: 21-23).

Tenemos que hacernos, por tanto, una idea muy amplia de sus colaboradores y de los encargos realizados a estos, que incluyen desde las consultas eruditas a los dibujos de los artistas que protegía.

\footnotetext{
4. Sobre el detalle heterogéneo y universal de sus colecciones, se incide en Montoya (2020: 13-15).

5. Para su fundamental aporte metodológico, véase Montoya (2020: cap. 2).

6. Las palabras de Caylus eran estas : «On s'apercevra facilement à certains traits d'érudition, que je n’ai point travaillé seul. En effet, M. L'Abbé Barthélemi a bien voulu me communiquer quelquefois ses lumières \& je pourrai marquer ce qui lui appartient, ainsi qu'a quelques autres de mes confrères de l'Académie» (Caylus, Recueil, t. I, 1752, Avertissement, p. XIV). Barthélemy fue «Garde» del «Cabinet du roi» (desde 1754-1795), coloquialmente «Cabinet des médailles».

7. En nuestro trabajo anterior exponíamos: «Algún contemporáneo suyo escribió que "tenía hacedores para todo" y que los abates Belley y Barthélemy eran "sus compositores” (2020: 12, n. 45). La cita correspondiente decía: «Queyrel (1995: 234). Fue François Pasumot en su Eloge du comte de Caylus (1766) publicado...». Equivocamos el autor de la nota, que no era Queyrel, sino Fumaroli (1995: 234). Con motivo de este trabajo hemos revisado el texto de Pasumot y para nuestra sorpresa no hemos encontrado la referencia ni a Belley, ni a Barthélemy. Por el contrario, el texto de Pasumot es muy generoso y agradecido con Caylus, y cuenta incluso que el conde le financió las tres cartas de sus memorias geográficas (Pasumot (1813 [1766]: 23).
} 


\section{La edición del Tirant: Caylus y Fréret}

A fecha de hoy, no se conocen los pormenores del encuentro entre Caylus y el Tirant, es decir, las circunstancias en que conoció esta novela y por qué se sintió atraído hacia ella. Pero la edición que patrocinó ha dejado huella. Primero, porque ofreció a los lectores de habla francesa una nueva novela de caballerías, y después, porque la traducción se acompañó de un Avertissement, que supuso el primer estudio crítico de ella.

Si atendemos al último estudio de Peeters sobre la obra conjunta de Caylus (originales y atribuidas), la novela salió de las prensas sin título de autor ni de traductor, como: Histoire du vaillant chevalier Tiran le Blanc, Londres [París], Aux dépens de la compagnie, 1737. La edición se repitió en 1740 (en Ámsterdam, Chez Weistein \& Smith, y en Londres) (Fig. 1) y nuevamente en 1775 (Londres). Después, en París, en 1783 y en 1787. Dos siglos más tarde, en 1997, esta misma traducción volvió a salir a la luz, en edición a cargo de Jean Marie Barberà, con un comentario de Mario Vargas Llosa y una noticia de Marc Fumaroli. ${ }^{8}$ Los estudios críticos inciden desde entonces en que se trató de una traducción bastante libre, con supresiones y cambios considerables respecto del texto original, por lo que se prefiere entenderla antes como una adaptación que como una traducción en sentido estricto. ${ }^{9}$

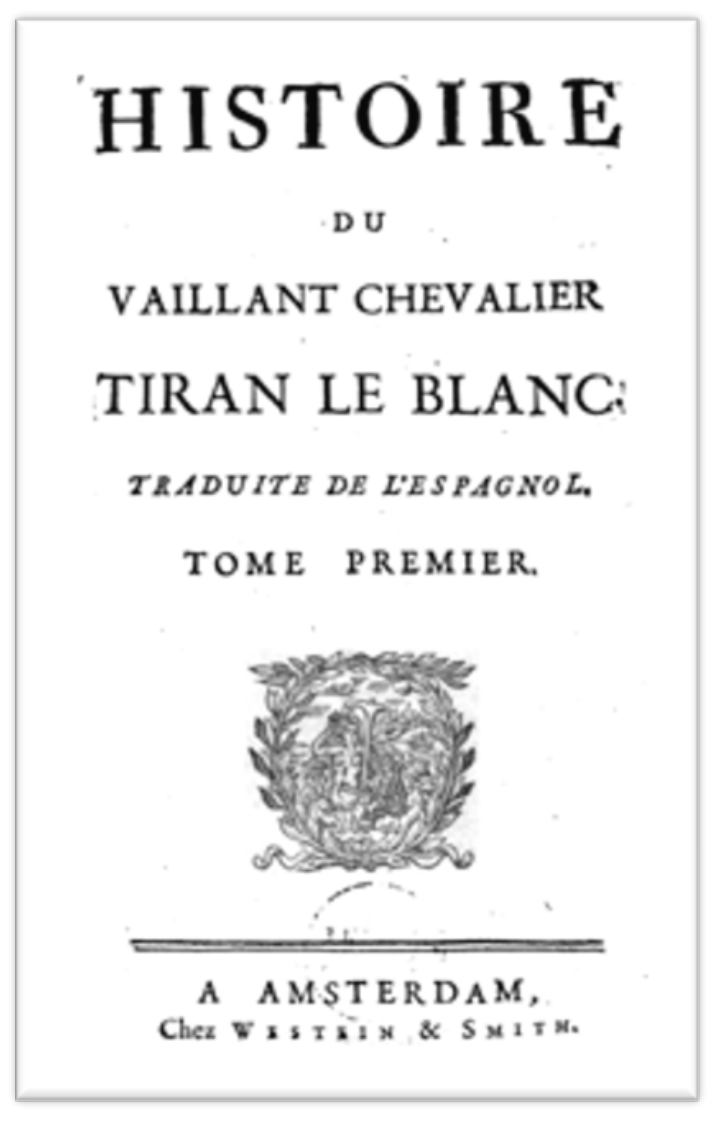

Fig. 1

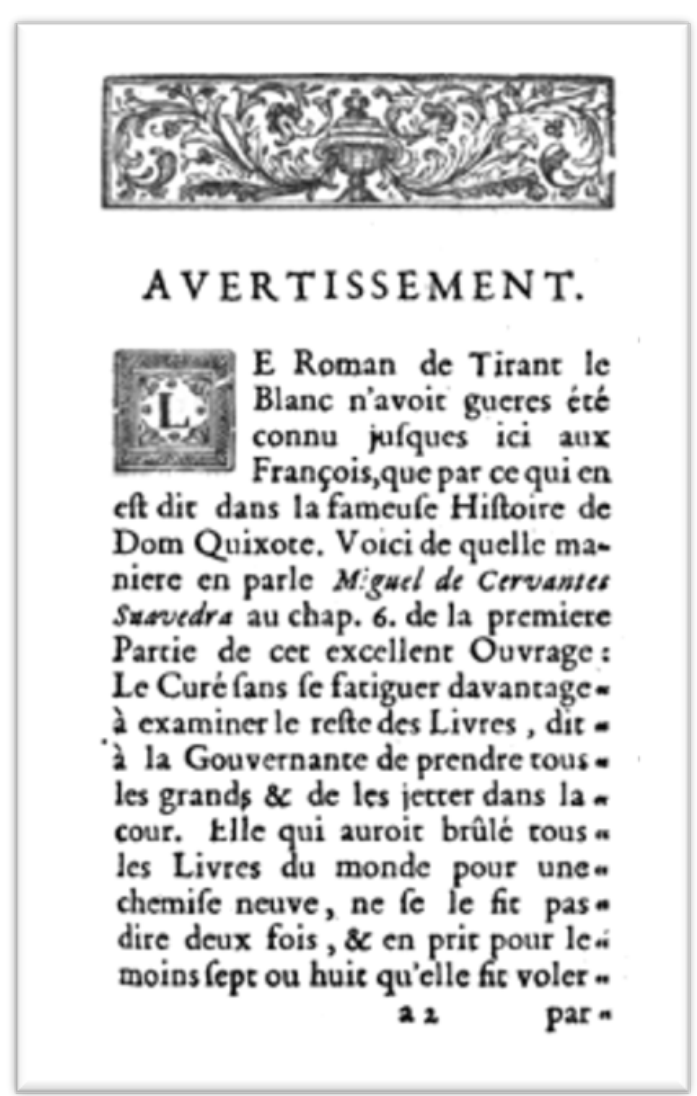

Fig. 2

8. Peeters (2004: 287-288). Respecto de las ediciones francesas recogidas en Beltran e Izquierdo (1997), Peeters añade la de 1783. Cfr. Vila (1997).

9. Es el caso del título del trabajo de Bensoussan (1997), «l’adaptation française ... »; o del estudio de Barberà (Martorell, 1997: 567-602). 
El Avertissement (Fig. 2) que precede la obra, y que tampoco tiene firma de autor, nos parece un notable estudio de crítica literaria para la época. ${ }^{10}$ Comienza con intensidad al reproducir pasajes de la obra maestra de Miguel de Cervantes en los cuales se hace mención del Tirant lo Blanc. ${ }^{11}$ Se transcriben párrafos traducidos al francés y luego en el original castellano, porque el crítico observa problemas en la traducción. Entre los textos reproducidos, sobresale el conocido enunciado que Cervantes pone en boca de uno de sus personajes, según el cual Tirant «es el mejor libro del mundo» ([1740]: III-XII). Después, el crítico informa que se sabe muy poco de la obra; en realidad: «El nombre, el país \& el siglo del autor de este libro, son absolutamente desconocidos» ([1740]: XI). De su propia lectura supone que el autor sea valenciano ([1740]: XII), conjetura que probablemente conoció las revueltas del año 1369 en Valencia contra el rey de Aragón Pedro IV ([1740]: XIII), deduce que vivió hacia el año 1400, por la referencia a una obra (Arbre des batailles) y afirma que no escribió con posterioridad a 1480-1485, por lo que en la novela se dice sobre África ([1740]: XIV). Cita «una crónica catalana de Miquel Carbonell» ([1740]: XXII) y concluye que Tirant pudo haber sido compuesta entre 1436-1443 y 1453 ([1740]: XxIV). Luego, vuelve sobre las palabras de Cervantes, para precisar que la afirmación «es el mejor libro del mundo» debe entenderse en relación al «estilo»y por comparación con otras obras del mismo género $([1740]: \mathrm{Xxv})$.

El crítico comenta a continuación la traducción del Tirant que se va a ofrecer al público francés. Teniendo como prioridad máxima el entretenimiento del lector, informa que el traductor se ha tomado «todas las libertades» que ha estimado necesarias para «abreviar», «suprimir»y «cambiar» el texto original, sin por ello dejar de conservar el retrato de las costumbres del siglo del autor ([1740]: XXVI-XXVII). Finalmente, ofrece una información del mayor interés. Asegura que la obra era «bastante rara» en la España moderna y desconocida más allá de la mención en la novela de Cervantes. Argumenta que la obra de Nicolás Antonio (su Bibliotheca) no hacía referencia a ella pese a tratar con gran detalle las novelas de caballerías ([1740]: Xxx-XxxI). En fin, solo se conocía una edición española -la castellana: Los cinco libros del esforçado y invencible cavallero Tirante el Blanco (Valladolid, 1511) - y una traducción al italiano debida a Lelio Manfredi, con tres ediciones (Venecia, 1538, 1566 y 1611) ([1740]: XXXI-XXXII).

Del conjunto, la cita del trabajo del bibliógrafo andaluz merece un comentario obligado, porque en la Bibliotheca Hispana Vetus (Roma, 1696), obra póstuma de Nicolás Antonio (16171684), que preparó Manuel Martí (quien sería más tarde deán de Alicante) por encargo del cardenal Manuel Sáenz de Aguirre, sí que se mencionaba la paternidad y origen del Tirant le Blanc. ${ }^{12}$ Se precisaba que Joan Martorell, del reino de Valencia, fue un escritor de aventuras fabulosas, autor de una obra titulada Tirant lo Blanch, impresa en Valencia en 1490, y que el mismo Martorell decía haberla antes traducido de un libro inglés al portugués, lo cual, al modo de ver del editor, era una ficción. Por lo tanto, el autor del Avertissement apenas dio credibilidad a esta nota, ya que insistió en que físicamente la obra solo se conocía en castellano e italiano.

Rocheblave, el más completo de los biógrafos de Caylus, entendió que este Avertissement era obra original del Conde, que venía a demostrar una «inteligente curiosidad por los asuntos de la

10. Se puede consultar el Avertissement en Martorell [1740]: III-XXXII.

11. Miguel de Cervantes Saavedra (1547-1616) y la primera parte de El Ingenioso Hidalgo don Quixote de la Mancha (Madrid, Juan de la Cuesta, 1605).

12. Antonio (1696, t. II: 183; col. 2, núm. 490). Véase infra, nota 31, cómo entendió su contemporáneo el P. Rodríguez, el citado texto. Lo conocemos también parcialmente traducido al inglés en los años 70 del siglo XVIII por Thomas Warton. Cfr. Anyó Oliver (2001). 
Edad Media». ${ }^{13}$ En ello parecía seguir a los editores de la Bibliothèque Universelle des Romans (París, 1783) que en breve nota identificaban sin mayor problema este «Prefacio luminoso», al igual que la traducción, como obra del mismo Caylus (Figs. 3 y 4$).{ }^{14}$

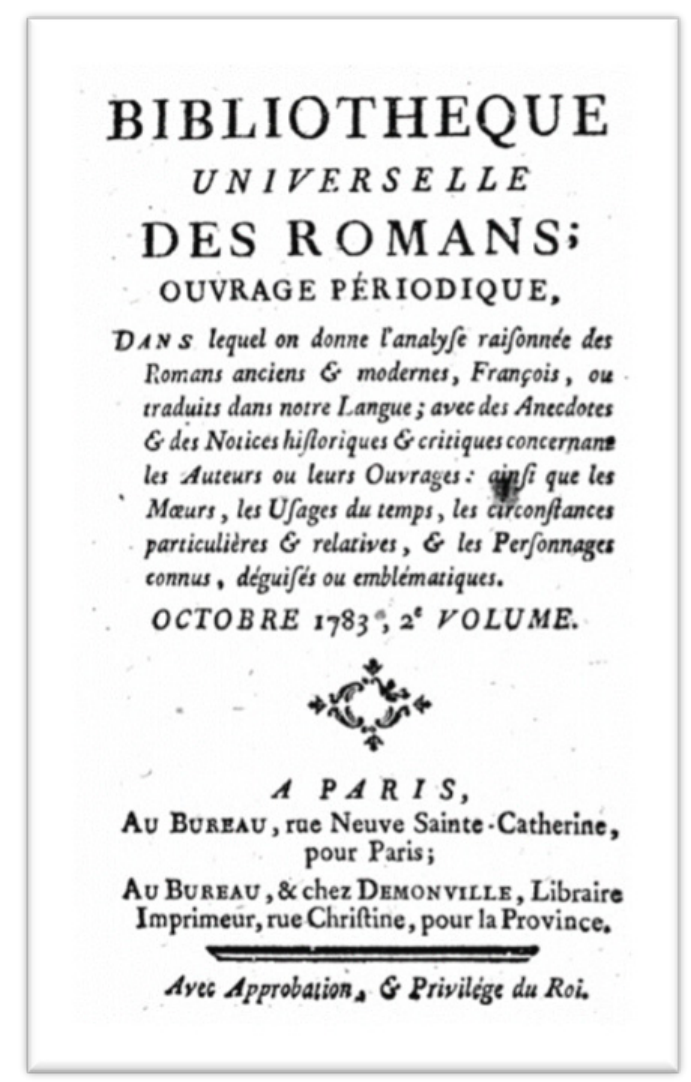

Fig. 3

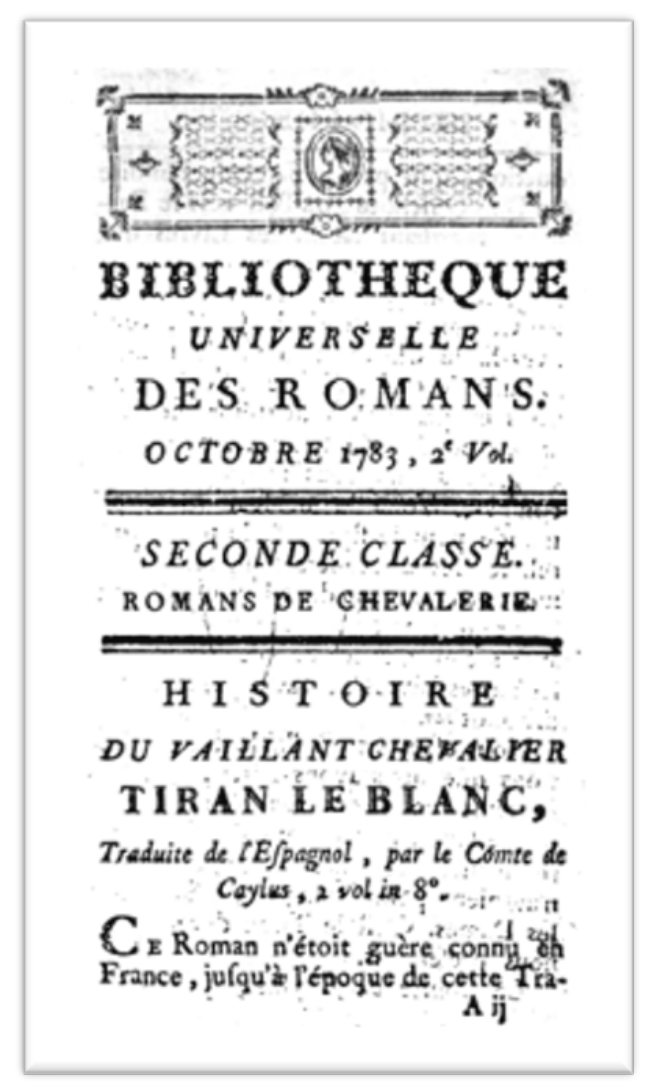

Fig. 4

Sin embargo, poco después del fallecimiento de Caylus, desde el Nouveau dictionnaire historique portatif (Ámsterdam, 1769), se sostuvo que el «Prefacio, las notas y una parte de la traducción de Tirant le Blanc» habían sido obra de Nicolas Fréret. Los editores del diccionario, una «Société de Gens de Lettres», describían a Fréret (1688-1749) como un abogado apasionado por la historia y la cronología, miembro de la Academia de Inscripciones y Bellas Letras de París desde los veinticinco años, reconocido en su tiempo por su erudición y como autor de numerosas memorias. ${ }^{15}$ Como curiosidad, recordaban que había estado preso en La Bastilla por un discurso sobre el origen de los franceses, que había sido socorrido por el filósofo ilustrado Pierre Bayle («el famoso escéptico»), que tenía diferentes escritos polémicos sobre temas de religión y que sabía muchísimo sobre teatro europeo. En paralelo, la semblanza ofrecida sobre el Conde Caylus en el

13. Rocheblave expuso: «Dans son Introduction à la traduction du roman espagnol, Tiran le Blanc, Caylus justifie l'importance de cet ouvrage en ces termes assez remarquables ... $\gg(1889$ : 46).

14. En la breve nota que antecede a la edición de 1783 del Tirant francés, se dice: «Le Comte de Caylus, qui en est le traducteur, dans une Préface lumineuse fixe l'époque de ce Roman en 1436...» (Martorell, 1783: 3-5). Para un estudio sobre esta edición, véase Vila (1997).

15. Sobre Fréret véase el Nouveau Dictionnaire (1769: II, 177). En GALLICA (Biblioteca digital de la Biblioteca Nacional de Francia) figuran como autores de esta obra Louis-Mayeul Chaudon (1737-1817) y sus colaboradores, Pierre-Jean Grosley (1718-1785) y François Moysant (1735-1813). La semblanza biográfica más conocida de Fréret es la de Bougainville (1756). 
mismo diccionario no aportaba mayor novedad, aunque le reconocía al Conde la paternidad de otros numerosos escritos (Fig. 5). ${ }^{16}$

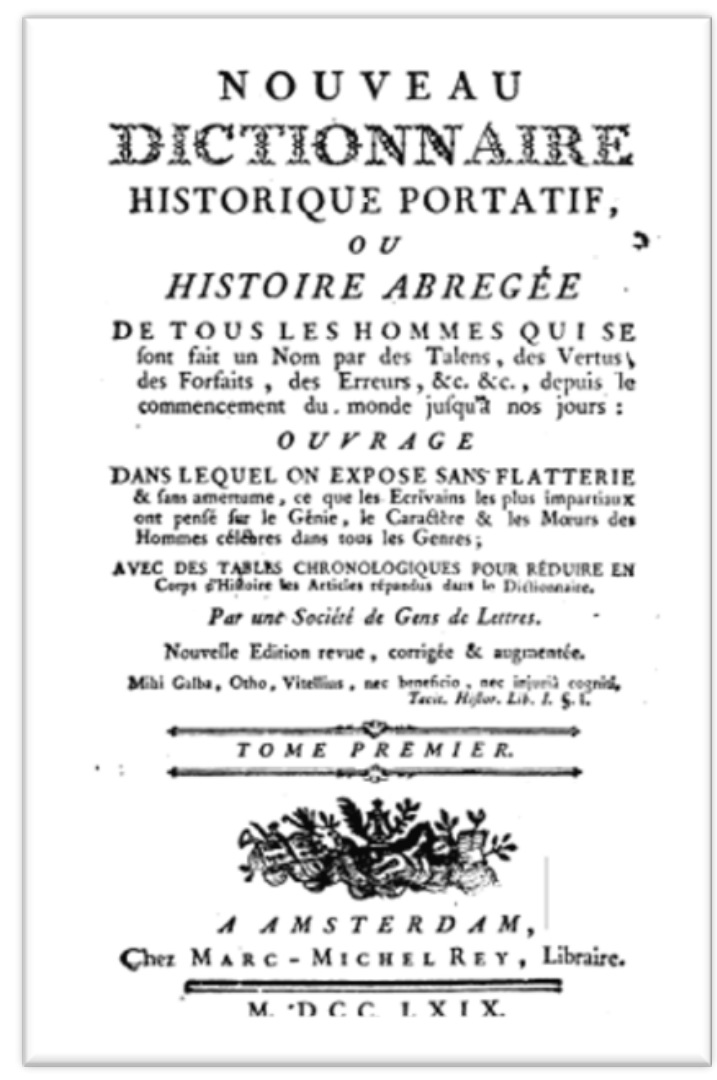

Fig. 5

Fréret es hoy considerado como el autor del Avertissement. ${ }^{17}$ Básicamente porque entre sus manuscritos, clasificados por Walckenaer, se tiene uno con este mismo título, aunque con la fecha de 1775. ${ }^{18}$ Debe tenerse presente, no obstante, que Fréret, secretario perpetuo de la Academia Real de Inscripciones y Bellas Letras (desde el 8 enero 1743), tiene una obra inmensa, sobre la cual ha existido no poca confusión y polémica que incluye más que los 20 volúmenes impresos en $1796 .{ }^{19}$ Debieran tomarse con cautela, además, algunas afirmaciones que he podido leer acerca de su relación con Caylus. Se ha dicho, por ejemplo, que «mantuvo una gran relación de amistad con el Conde de Caylus» y que fue el Conde quien «lo liberó de la Bastilla, donde Fréret había pasado tres meses $\gg .{ }^{20}$ Sin embargo, en ninguna de las semblanzas biográficas de Caylus se menciona una especial relación con Fréret, y entre los protectores de la juventud y madurez de Fréret figuran, según el propio Walckenaer, otros nombres (Rollin, el abate Sevin, Félibien, el abate Barthélémy, el abate La Bletterie o Bougainville). Pero Caylus no aparece.

16. Sobre Caylus, véase el Nouveau Dictionnaire (1769: I, 458-459).

17. Véase Calvo (1991) y Minervini (1993). La referencia fundamental es el estudio de Simon (1961).

18. Dice exactamente: «Avertissement au roman de chevalerie intitulé, Histoire du vaillant chevalier Tiran le Blanc, traduit de l'original catalan, de Marstorabie [Martorell ?], par le comte de Caylus, 2 vols in $8^{\circ}$. Londres, 1775, 3 vol., i-12» (Walckenaer, 1850: 21).

19. Cfr. Grell y Volpilhac-Auger (1994).

20. Martines Peres (2006: 97). 
Hasta aquí, se podría reconocer que la edición francesa del Tirant le Blanc la habría patrocinado Caylus, la traducción/adaptación sería obra del mismo Caylus, y Fréret el probable autor del Avertissement. Pero se podría unir a ese grupo un tercer personaje, considerando las relaciones traspirenaicas en esos años.

\section{Desde el entorno de Gregorio Mayans: Jean-Baptiste Souchay}

Mientras se publicaba el Tirant en francés, Gregorio Mayans y Siscar (1699-1781), figura primera de las letras valencianas del siglo XVIII, era bibliotecario real (1733-1740) y residía en la corte de Madrid. Venía de regentar la Cátedra de Derecho en la Universidad de Valencia, y trabajaba en la edición de sus famosos epistolarios, el suyo propio, Epistolarum libri sex (Valencia, Bordazar, 1732) y el de su maestro, el deán Manuel Martí, el famoso Epistolarum libri duodecim (Madrid, Juan de Zúñiga, 1735) que recibió el apoyo del embajador inglés Benjamin Keene. Además, por este tiempo compuso su obra más famosa en castellano, la Vida de Miguel de Cervantes Saavedra, destinada a ser incorporada en una edición de lujo del Quijote (Londres, 1738).21

En este último trabajo, Mayans hacía una mención breve a la novela del Tirant. Contraponía el entusiasmo de Cervantes con el rechazo por las novelas de caballerías del humanista Juan Luis Vives (Valencia, 1492-1540). ${ }^{22}$ Como explica Mestre (2006), poco más podía hacer Mayans, puesto que sus búsquedas de algún ejemplar del Tirant eran infructuosas en las bibliotecas de Madrid y de Valencia, lo que queda explícito en las cartas que escribía en diciembre de 1736 a Giuseppe Ottavio Bustanzo, secretario de la República de Génova en Madrid, y al canónigo valenciano José de Castellví y Coloma (1677-1739) ${ }^{23}$ En la primera de estas cartas, Mayans analizaba el pasaje de elogio de Cervantes, en términos muy clarificadores:

Sólo sé que es uno de los pocos libros de cavallerías que se libraron del fuego por la absolución del Licenciado Pedro Pérez, juez egecutor en aquel riguroso examen de los malos libros de D. Quijote. (apud Mestre, 2006: xxv).

Otro de los corresponsales de Mayans fue el abate Jean-Baptiste Souchay, y las cartas intercambiadas entre ambos, fechadas entre 1731-1735, dejan saber ante todo el interés que tenía Mayans por ganarse el favor de cardenal Hércules Fleury, primer ministro de Francia (Mestre, 2012). En el intento de conseguir el patrocinio del Cardenal para las empresas culturales que proyectaba, Mayans le dedicó su Epistolarum libri sex (Valencia, 1732; reimpreso en Leipzig, 1737) y Souchay fue quien se encargó de hacer llegar los ejemplares impresos. La obra de Mayans se distribuyó por París con el favor de Souchay, pues de este modo llegó también a la Academia de Inscripciones y Bellas Letras e incluso a Baltasar Patiño, marqués de Castelar, el embajador extraordinario de España (Peset, 1975: 63-64). Según veremos más adelante, Caylus conoció y elogió esta obra en su Recueil.

21. «Vida de Miguel de Cervantes Saavedra. Su autor Don Gregorio Mayans i Siscar», en Vida y hechos del ingenioso hidalgo Don Quixote de la Mancha. Compuesta por Miguel de Cervantes Saavedra. En quatro tomos. Parte primera Tomo primero, Londres, J.y R. Tonson, 1738, pp. 1-103. Mayans dedicó esta Vida a Lord Carteret, y toda la lujosa edición fue dedicada a la Condesa de Montijo. Se incluyen 68 láminas de J. Vanderbank. Véase Rius (1895: I, 34-35).

22. Mayans escribió: «El mismo Cervantes le alaba mucho, lib. 1, cap. VI. Pero Vives le vitupera con todos sus semejantes». Vives había arremetido contra «los libros pestilenciales, cuales son en España: Amadís, Esplandián, Florisando, Tirante, Tristán, a cuyos despropósitos no se pone término ... ». Véase Mayans (2006: 97-98 y 107). Para el ataque de los humanistas del XVI a los libros de caballerías -Vives fue uno de los primeros en vituperarlos, pero no el único-, y en concreto a Tirant, véase Beltran (2019b).

23. Mestre (2006: xxv). Sobre Castellví, véase Felipo Orts (2013). 
Para mayores coincidencias, la semblanza biográfica de Souchay la compuso el citado Nicolás Fréret. Según este esbozo, Jean-Baptiste Souchay (1688-1746) había sido miembro de la Academia Real de Inscripciones y Bellas Letras de París (desde 1726), profesor de Elocuencia latina en el Colegio Real de París (1732) y canónigo de la Catedral de Rodez, en Occitania (desde 1734). ${ }^{24}$ Pero más tarde - y de ahí su importancia en el tema que aquí nos concierne-, Souchay iba a ser identificado por uno de los grandes amigos de Mayans, como el autor de la traducción francesa del Tirant. Vicente Ximeno — de quien nos ocupamos más adelante - publicaba en 1749 que:

Juan Bautista Souchay, Canónigo de Rodez, Académico de la Academia Real de las Inscripciones y Letras humanas y profesor de Eloquencia en el Colegio Real de París, traduxo y publicó en francés cosa de diez años atrás [ca. 1739] a Tirant lo Blanch, única obra de este autor, que antes de Miguel de Cervantes Saavedra tuvo el primer lugar entre los libros de caballería, si bien Juan Luis Vives, en el libro que allí dexo citado, le reprehende con razón... (1749: II, 374)

En este mismo sentido escribía Mayans al editor suizo Gabriel Cramer el 6 de marzo de 1751: «También quisiera conseguir a Tirant lo Blanc traducido por el abad Souchai en francés». ${ }^{25}$ Por tanto, y si atendemos a las fechas de vida de Souchay, se deduce que la edición patrocinada de Caylus podría haber sido traducida por este abate y prologada por su biógrafo, Fréret. Esto sugiere la participación conjunta en la edición conocida, de Caylus, Fréret y Souchay. Desde esta perspectiva, los nombres de Fréret y de Souchay pudieran encajar entre el gran número de colaboradores que trabajaron para Caylus, que recibieron sus encargos, o que le asistieron en sus diferentes proyectos. El responsable mayor de la empresa seguiría siendo Caylus, con la participación anónima y acaso secreta de Fréret y de Souchay.

De todas formas, en el mismo siglo XVIII, Caylus es tenido como la cabeza del proyecto, traductor y también autor del Avertissement. La edición completa de las Euvres badines del Conde es bastante categórica al respecto. ${ }^{26}$ Este recopilatorio, que se presenta elaborado sobre la base de una investigación muy rigurosa, se inicia con la reimpresión del Tirant francés. Aquí, en el Prefacio, el editor asegura que el Conde tradujo novelas del castellano y del italiano, y en la Advertencia correspondiente afirma con contundencia: «La primera novela de caballerías traducida por el Conde de Caylus fue la Histoire du vaillant Chevalier Tiran le Blanc». A continuación, el editor reimprime el Avertissement de la edición original como Avertissement du traducteur imprimé en tête de l'édition de 1740, es decir, como una anotación del propio traductor (entiéndase, de Caylus). Garnier, el editor de las Euvres badines, no concibió a otra persona para ello, aunque en otros asuntos y temas no tuviera el menor problema en precisar aquello que no era de la autoría de Caylus. ${ }^{27}$

\footnotetext{
24. Fréret (1753). Walckenaer (1850: 19) le llama «Abbé Souchet».

25. Mestre (1976: 620). Cramer introdujo a Mayans directamente con Voltaire; estos dos últimos mantuvieron una importante correspondencia en torno a temas teatrales (Mestre, 2003).

26. Caylus (1787, t. I) incluye: «Préface de l'éditeur» (pp. v-xvi); «Avertissement de l'éditeur» (pp. xxi-xxiv); «Avertissement du traducteur imprimé en tête de l'édition de 1740» (pp. 25-48) e «Histoire du vaillant chevalier Tiran Le Blanc» (pp. 49-378). El editor de las Ouvres badines se identifica siempre con Charles-Georges-Thomas Garnier (1746-1795).

27. Garnier reconoció, por ejemplo, obras que eran de la autoría de Chevrier y de Grosley (1746-1795: vii). Véase la nota anterior.
} 


\section{Apuntes breves. Difusión de Cervantes y atribución errónea a Caylus}

Sin duda la literatura española gustaba e interesaba. La edición francesa del Tirant de Caylus consiguió rescatar y reintroducir en el circuito de impresión una novela olvidada y, además, aportaba un primer estudio crítico que ponía de relieve una relación especial: la obra del Tirant había sido elogiada por Cervantes por su estilo, como «el mejor libro del mundo».

Casi paralelamente apareció la Vida de Cervantes compuesta por Gregorio Mayans, que era la primera semblanza biográfica del autor del Quijote, en la que se ofrecía también un apunte sobre los elogios a Tirant lo Blanc, aunque sin entrar en detalles. Este trabajo de Mayans se difundió ampliamente y los lectores de habla francesa pudieron adquirirlo en la traducción realizada por Pierre Daudé (Ámsterdam, 1740) ${ }^{28}$ El éxito fue tal, que solo en 1751, en Madrid iban por la quinta impresión y en Francia por la sexta. ${ }^{29}$

El presbítero Vicente Ximeno (1691-1764), amigo y corresponsal de Mayans, tampoco dejó pasar la oportunidad de poner de relieve esta relación especial, en sus Escritores del reyno de $\mathrm{Va}$ lencia (Valencia, 1747-1749, 2 vols.). En el tomo primero, Ximeno informaba a sus lectores que «Pedro Juan Martorell» (sic) había escrito en «lemosín» el libro de caballerías Tiran lo Blanch publicado en Valencia en 1480 (sic). Lo había visto así en una librería de Roma el «cavallero barcelonés» Antonio Bastero, quien registraba el hecho en su Crusca Provenzale (Roma, 1724). Después de comentar la mención de Nicolás Antonio, Ximeno se detiene en los elogios de Cervantes, y reproduce otros fragmentos: el Tirant era "un tesoro de contento, y una mina de passatiempo", y su personaje principal, citado con mucha distinción, «El nunca como se deve alabado Tirante el Blanco» (Ximeno, 1747: I, 12-13).${ }^{30}$ En el tomo segundo, según hemos indicado, Ximeno no dejó pasar la oportunidad de decir sobre la obra, que «antes de Miguel de Cervantes Saavedra tuvo el primer lugar entre los libros de caballería» (Ximeno, 1749: II, 374).

Es bastante sintomático, a propósito de lo que estamos comentando, que en la Biblioteca Valentina del Padre Josep Rodríguez (1630-1703), impresa por este tiempo, pero finalizada muy a principios de siglo, no se diga nada de la relación entre Cervantes y el Tirant. ${ }^{31}$ A mediados del siglo XVIII, en cambio, a ningún interesado en la obra del Tirant se le escapaba que Cervantes la había elogiado de maneras y modos diferentes en su Quijote. ${ }^{32}$ Era como un reclamo, una nota de distinción que no se podía dejar pasar por alto. Y esto ocurría mientras la obra cervantina multiplicaba sus lectores. En España, en 1752, el Marqués de la Ensenada -titular de varias secretarías

28. La vie de Michel de Cervantes Saavedra, par Don Gregorio Mayans y Siscar, Bibliothécaire du Roi d'Espagne. Traduite de l'Espagnol, avec quelques remarques du Traducteur, par le Sieur D.S.L. (Ámsterdam, Chez François Changuion, 1740). El traductor anónimo se identifica con Pierre Daudé según Rius (1899: II, 5-6). Las menciones al Tirant en esta obra, véase Mayans (1740: 24 y 215 ).

29. Se cuentan trece ediciones solamente en el siglo XVIII según Mestre (2006: XXXVIII-XXXIX).

30. La mención de Ximeno equivoca el año de 1480 y el nombre «Pedro Juan», pues el canónigo Antoni Bastero i Lledó, en La Crusca provenzale (Roma, 1724), escribió correctamente que la obra era de la autoría de «Mossen Joanot Martorell», que la terminó «Martín Giovanni de Gualba», y que se publicó en Valencia el año de 1490. Véase Martines (1993).

31. Dice Rodríguez: «Juan Martorell. Valenciano. Ciudadano. Escrivió en idioma Lemosín un libro con este informe título: Tirant lo blanch. Assi lo trae Don Nicolás, in Biblioteca Veteri, Tom. 2, lib. 10, cap. 9, fol. 183, num. 490 explicando que es una Relación de Fábulas, que se imprimió en Valencia, año 1480 en folio, y que en ella afecta el Autor, que le traduxo de Inglés (que parece seria el original) en Portugués, y de Portugués, en Valenciano, año 1460. Con que en dichos Idiomas sería perito, nuestro Escritor. No tengo otra noticia» (1747:276).

32. Sobre Tirant, el Quijote y Cervantes, remitimos a los estudios de Beltran (2019a y 2005). 
de Estado y hombre fuerte durante el primer reinado de Fernando VI, patrocinador declarado de estudios anticuarios- también propuso a Mayans llevar adelante una lujosa edición del Quijote. ${ }^{33}$

La segunda cuestión sobre la que quisiera llamar la atención a propósito de la obra de Cervantes, alude directamente a Caylus. Desde la Academia de Troyes (en la Champaña francesa), en 1744 se publicó, sin nombre de autor, un «Project de voyage en Espagne pour constater un fait important de l' histoire du chevalier Don Quichotte» (Fig. 6) ${ }^{34}$ Este texto fue insertado años después en las Euvres badines de Caylus, formando parte del tomo decimoctavo, con los escritos que eran atribuidos al Conde (Caylus, 1787) (Fig. 7). Aunque por algunos años reinó confusión al respecto, sabemos que los autores fueron jóvenes troyanos animadores de una sociedad literaria local ${ }^{35}$ y que el citado «Proyecto» habría sido obra del jurista André Lefèbvre (Troyes, 17171768). ${ }^{36}$ Otros lo atribuyen a Pierre-Jean Grosley (Troyes, 1718-1785), también jurista, literato e historiador, del que se conservan cartas amables intercambiadas con Caylus y que fue colaborador del diccionario que anunció a Fréret como autor del Tirant. ${ }^{37}$

El citado «Proyecto» debe entenderse, por tanto, lejos de Caylus, entre las disertaciones fantasiosas de la «Academia troyana», que se elaboraron para contrarrestar con sátira e ironía la mucha gravedad otorgada a ciertos temas. En el pretendido viaje a España, el «hecho» que había que «constatar» o comprobar históricamente era «la muerte del pastor Crisóstomo, muerto de amor por la bella Marcela»; en la discusión, la cita a la Vida de Cervantes de Mayans lleva a concluir «cuánto la historia de don Quijote es importante para esclarecer la historia universal» (1744: 95 y 101-102). Estamos, pues, ante un ingenio con ganas de burla y muy lejos de un proyecto real de viaje, como proponía García Mercadal (1999: 417).

33. Como es sabido, esta edición que incorporaba material recogido por Mayans no se llevó a cabo en tiempos del Marqués de la Ensenada, sino en 1797-1798. Véase Mestre (2006: XLVII).

34. A decir de Rius (1899: II, 233), el proyecto «se leyó» en la citada Academia el 16 de mayo de 1741, se publicó en sus Mémoires (Troyes, 1744), y fue el autor J-B. Grosley, según Dumaine.

35. Fueron siete los jóvenes que conformaron esta sociedad que por diversión tomó el nombre de Académie des sciences, inscriptions, belles-lettres, beaux-arts. Se reunieron por primera vez el 13 de julio de 1742 y por última vez, el 6 de enero de 1745. En este tiempo compusieron sus disertaciones, que publicaron en un único volumen, modificado a lo largo de sus sucesivas ediciones. Véase Payen (1848).

36. Según Payen (1848: 4 y 12-13), Lefèvre insertó algunas piezas de su autoría en la segunda edición de las Mémoires de l'Académie des sciences, inscriptions, belles-lettres, beaux-arts é, nouvellement établie à Troyes en Champagne (Troyes - París, 1756), entre las cuales «Un projet de voyage en Espagne pour constater un fait important de l' histoire de Don Quichotte». Las Euvres badines de 1787 lo reproducen.

37. No conocemos los argumentos de Dumaine para sostener que Grosley fue el autor. Para las cartas entre Grosley y Caylus, véase Vernière (1978). 


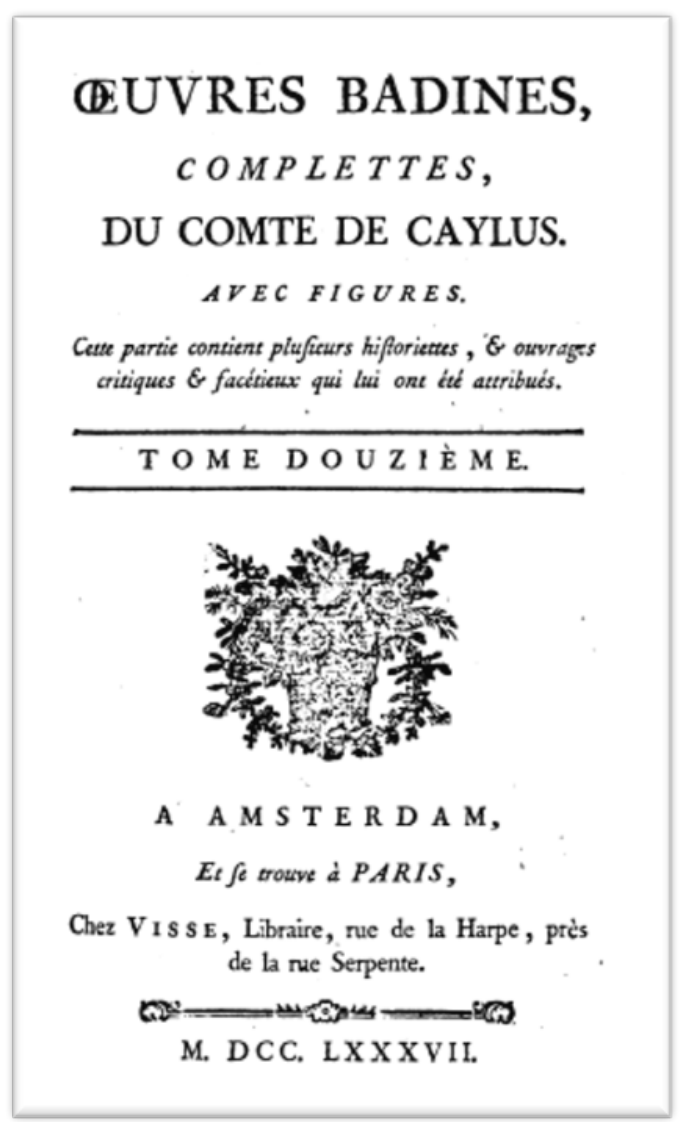

Fig. 6

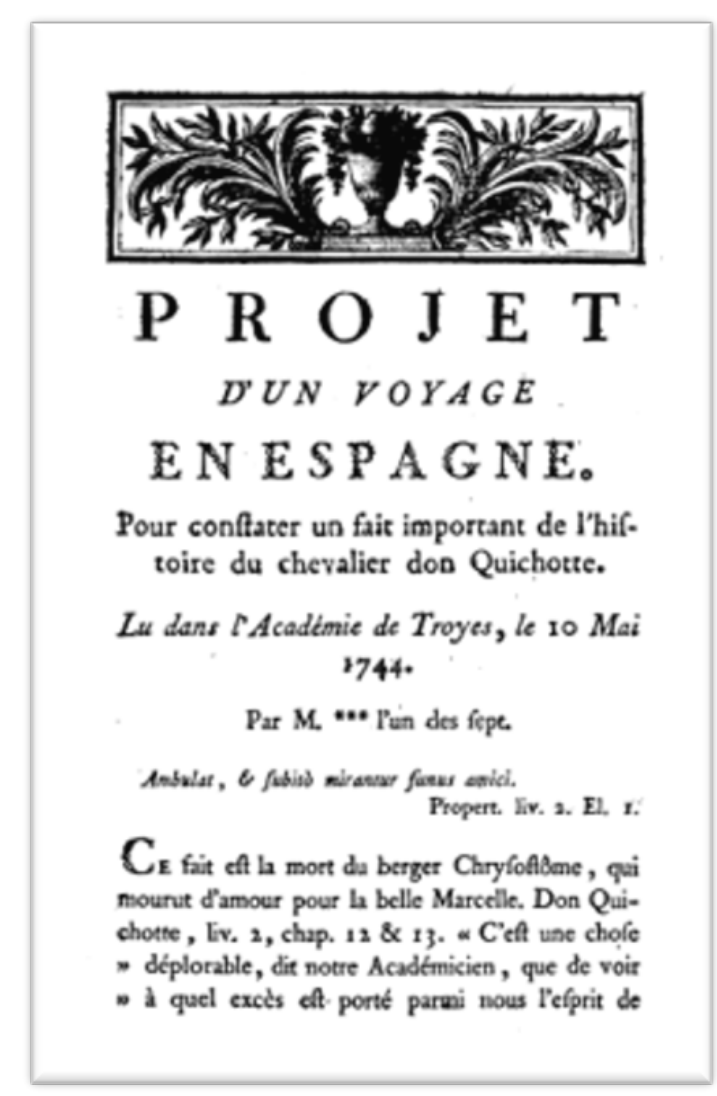

Fig. 7

\section{Antigüedades valencianas: los Caylus y Mayans}

En la obra mayor de Caylus, las antigüedades de España ocupan un lugar especial, representadas por materiales procedentes de Valencia, Cataluña y Cádiz, y aún con algún alcance a su imperio transatlántico. ${ }^{38}$ Añadiremos aquí algunas puntualizaciones, recordando que las relaciones de Caylus con el mundo cultural valenciano -epistolares, ciertamente- lo fueron cuando menos de dos tipos. ${ }^{39}$ En el terreno familiar, porque Caylus tenía aquí a un pariente muy próximo en un altísimo puesto, y en el campo de la erudición, como corresponsal de Gregorio Mayans y Siscar, según se informa en los volúmenes del Recueil de 1756 y de 1761.

El familiar que interesa aquí es el Duque de Caylus, Claude Abraham de Tubières-Grimoard de Pestels de Levis, tío paterno en primer grado del Conde. Nacido en Montauban-de-Bretagne (Rennes) en 1672, falleció en Valencia el 19 de julio de $1759 .^{40}$ Comenzó su carrera militar en Francia con diecisiete años, y tras un duelo y un destierro, pasó a servir al rey de España en 1701.

38. Remitimos a Montoya (2020: cap. 3) para todos los detalles.

39. Excluimos el entusiasmo de Caylus, a su paso por Nápoles en abril de 1715, por la obra del pintor valenciano José de Ribera (1591-1652), en Italia llamado Jusepe Ribera, «Lo Spagnoletto»), que ha estudiado Alzaga (2004:103-106).

40. Nos basamos en la renovada biografía de «Thubiéres de Grimoard, Claude-Abraham», que ofrece el Diccionario Histórico Español de la Real Academia de la Historia, firmada por Ceballos-Escalera (2021; en línea). En Montoya (2020: 36) citamos la semblanza aparecida en la edición impresa de dicho Diccionario (2013), firmada por Rama Patiño y Vázquez Lijó. La biografía que ofrece 
Derivado primero a los ejércitos de Flandes, hacia 1704 lo encontramos en Extremadura y después en diferentes campañas militares por Cataluña. Obtuvo el Toisón de Oro (1716), fue Capitán general de Galicia (1722) y tras ascender a Capitán general de los Reales Ejércitos (1734), culminó su carrera como Capitán General de Valencia (1735), cargo en el que se mantuvo durante 22 años. Casado desde 1726 con Bernardina de Villacís (1695-1742) hija del conde de Peñaflor de Argamasilla, el Caballero Caylus obtuvo primero el título nobiliario de Marqués de Caylus y luego, el de Duque de Caylus con la Grandeza de España en 1742.

En materia de antigüedades, el nombre del Duque de Caylus aparece en 1745 directamente vinculado a los hallazgos de un mosaico en el lugar de Sagunto, cuya fama se encargó de promocionar su sobrino, el Conde de Caylus, a partir de información transmitida directamente por Gregorio Mayans. El presbítero Agustín de Sales (1707-1774), recordaba que: «con el motivo de componer el Camino Real de Valencia según mandó el Señor Duque Queylus, cavando al lado de dicho camino junto al Monte del Castillo», el día 19 de abril «se descubrió un pedazo de pavimento a lo Mosayco». ${ }^{41}$

Tuvimos ocasión de precisar que el Duque informó a Madrid de los señalados descubrimientos, y cómo a partir de aquí se comisionó a Miguel Eugenio Muñoz y Lucientes (1706-1773), Oidor de la Real Audiencia de Valencia, «para excavar y reconocer» el mosaico y otros vestigios de la antigüedad en el lugar. ${ }^{42}$ Luego, siempre durante su gestión como Gobernador de Valencia, por orden real, el mosaico de Sagunto quedó protegido con «una caseta»; un hecho absolutamente inusual para la época.

Casi una década después, en 1756, Caylus ofreció en su Recueil, una lámina y explicación de dicho mosaico, agradeciendo personalmente a su corresponsal:

\begin{abstract}
presento en esta lámina el diseño de un pavimento de mosaico, que sirvió en el Templo de Baco, levantado en la antigua Sagunto, hoy Morviedro. Debo esta pieza a la cortesía del Sr. Mayans, cuyo mérito se conoce en la República de las Letras. Él tuvo la amabilidad, a petición mía, de mandarlo dibujar en el lugar, y yo copio su sentimiento, atribuyendo este antiguo pavimento a los restos del Templo de Baco [...]. De acuerdo con lo que está marcado en la parte inferior del dibujo coloreado, que el Sr. Mayans me envió, este pavimento de mosaico ha sido descubierto en el gran camino de Sagunto, en el mes de abril de 1745 \& los sombreados en diagonal, marcan lugares destruidos por los ignorantes que se llevaron piezas. (Recueil, t. II; 1756: 365-366)
\end{abstract}

Las ruinas de Sagunto eran célebres, especialmente desde que el anfiteatro fuera estudiado y excavado por Manuel Martí Zaragoza (1663-1737), el deán de Alicante, ya citado en este trabajo como maestro de Mayans, y antes, como editor de la obra de Nicolás Antonio. Mayans, que conocía estos trabajos, contribuyó a su divulgación a través de los dos epistolarios que publicó, y estas noticias llegaron a Caylus. En el Recueil, el Conde cita textualmente un pasaje latino del Epistolarum libri sex, tomado de la correspondencia intercambiada con el citado deán. ${ }^{43}$ Caylus apreció y

Ceballos-Escalera es muy completa, pero claramente equivoca los nombres de los padres de Claude Abraham, que no fueron Jean de Thubières y Madeleine de Bourbon. Remitimos a la genealogía de los Caylus en Courcelles (1824: 15-18).

41. A. Sales, Explicación que del Pavimento de Sagunto hizo el Doctor Agustín Sales Pbro. Académico Valenciano (mss.), apud Arasa i Gil (2012:348).

42. Muñoz, además de Oidor de la Real Audiencia de Valencia (1742-1772), fue historiador y académico de la Real Academia de la Historia (desde 1739) y escribió diversas obras, casi todas relacionadas con la historia del Derecho.

43. Véase Montoya (2020: 38) para la trascripción y traducción del texto latino. 
disfrutó verdaderamente de esta obra, y alabó todo lo que en ella tenía que ver con antigüedades españolas. Su dictamen era concluyente:

sin hacer un catálogo de todos los libros excelentes que España ha producido sobre la antigüedad, yo me contentaré con citar, como uno de los últimos, las cartas de D. Mayans, de las que ya he hablado: ellas tratan de diferentes materias, pero lo que se encuentra sobre las antigüedades, no puede ser ni mejor escrito ni mejor escogido, en una palabra, ni presentado con mejor acierto. Podemos leer, para estar convencido de lo que avanzo, la bella \& sabia Descripción del Teatro de la antigua Sagunto, hoy día Murviedro; es de D. Manuel de Martí, Deán de Alicante. (Recueil, t. IV; 1761: 358-359)

Sagunto se convirtió, en un lugar de visita obligada para los amantes de las antigüedades que pasaban entonces por Valencia. En el verano de 1753, Gregorio Mayans y el Conde de Harrach, realizaron una visita al antiguo teatro, al castillo y al mosaico de Baco, y además revisaron y copiaron veintiséis inscripciones latinas y una ibérica. ${ }^{44}$ En esta ocasión, el aristócrata vienés fue cumplimentado por el capitán general Duque de Caylus, y este hecho es importante, porque por enero de 1754 Mayans remitió a dicho Conde de Harrach -ya de vuelta en su país- una carta con las inscripciones que habían visto juntos, la que fue «redactada a petición del Duque de Caylus ${ }^{45}$

Más allá de esta cita, las posibles relaciones personales establecidas entre Mayans y el Duque de Caylus nos resultan desconocidas. Sabemos, sí, que el famoso médico Andreu Piquer i Arrufat (1711-1772), tuvo una estrecha relación con ambos; porque visitaba al Duque y a su esposa, y era amigo íntimo de Mayans desde 1741; incluso, sabemos que Piquer solicitó en alguna ocasión la intervención del Duque para favorecer a su amigo. ${ }^{46}$

Según se desprende de las referencias citadas, el Duque de Caylus fue un militar de alto rango, que durante du gobierno en Valencia mostró una gran sensibilidad hacia los temas anticuarios. Lamentablemente, no sabemos de comunicaciones directas, en este sentido, con su sobrino, el celebérrimo Caylus. Apenas dos noticias y en extremos cronológicos. La primera nos remite a la juventud de Caylus; en la correspondencia de su madre, se dice que el tío estará «encantado de ver» a su sobrino en España, si el regimiento de éste se traslada a Cataluña. ${ }^{47}$ La segunda noticia que tenemos es a raíz de la muerte del Duque de Caylus, fallecido viudo y sin hijos. El ya muy rico Conde de Caylus, que fue su heredero, rechazó el título y la Grandeza de España que le tocaba por sucesión. ${ }^{48}$

Seguramente un estudio en profundidad sobre el Duque de Caylus permita conocer detalles de lo que puede interpretarse como un distanciamiento. A los Caylus, tío y sobrino, les separaban veinte años, pero llevaban vidas relacionadas: el Duque gobernaba Valencia mientras su sobrino imprimía en Francia el Tirant, una obra valenciana que no se encontraba en las bibliotecas españolas; después, el Duque favoreció localmente los asuntos anticuarios del reino que gobernaba,

44. Martinez Aloy (1908).

45. Peset (1975: 146-148). Se trata de Ernst Guido Graf de Harnach-Rorhau (1723-1783), Conde de Harrach, quien a su paso por Valencia se alojó en casa de Juan Basilio de Castellví y Coloma, Conde de Cervellón (1675-1754), por largos años residente en Viena. Cfr. Mas y Vellón (2017).

46. Peset (1975: 230-231 y 238).

47. Raunié (1881:301).

48. Raunié (1881: 330-331). El biógrafo del Conde de Caylus, Le Beau (1767: xxI) escribió: «Le Roi d’Espagne en conférant la Grandesse au Duc de Caylus, avoit rendu cette dignité réversible à ses héritiers portant le nom \& les armes. M. le Comte de Caylus négligea de recueillir cette éclatante portion de l’héritage de son oncle. Son âge, son genre de vie, son indifférence pour les honneurs le retinrent dans l'état ou il avoit voulu vivre jusqu’alors; il n'étoit sensible qu 'a la gloire des arts \& des lettres». 
mientras su sobrino los publicitaba. Los títulos de Conde de Caylus y de Duque de Caylus (con la Grandeza de España), acabaron unidos en un sobrino común. ${ }^{49}$

\section{Bibliografía}

Alzaga Ruiz, Amaya (2004), «La visión directa de José de Ribera a través de los Voyages en Italie de los franceses en los siglos XVII y XVIII», Espacio, Tiempo y Forma, serie VII, Historia del Arte, 17, pp. 97-119.

Antonio, Nicolás (1696), Bibliotheca Hispana Vetus, Roma, Ex Typographia Antonii de Rubeis, t. II.

Anyó Oliver, Joaquim (2001), «Tirant lo Blanc a Anglaterra. Notes de recepció literària», Estudis Romànics, 23, pp. 221-227.

Arasa I GIL, Ferran (2012), «"Dar alguna luz à la historia antigua”. Les primeres excavacions arqueològiques al País Valencià en el segle XVIII», Archivo de Prehistoria Levantina, XxIX, pp. 341-378.

Beltran, Rafael (1991), «Llegir Tirant lo Blanc (I i II)», El Temps, Fasc. 24-25. <http://www. cervantesvirtual.com/obra/llegir-tirant-lo-blanc-i-i-ii-0/>

(2005), «Cervantes i Tirant lo Blanc», Norberto Piqueras (coord.), Del Tirant al Quixot: la imatge del cavaller [Exposició: Sales Estudi General i Duc de Calabria, La Nau, Universitat de Valencia 9 febrer - 10 abril 2005], Valencia, Universitat de València, pp. 55-62.

(2019a), «Du chevalier Tirant au chevalier Quichotte: la critique humaniste des romans de fiction et le détachement ironique de Cervantes», Tirant, 22, pp. 239-258.

(2019b), «"Humos escuros y espesas nieblas" en los primeros ataques a los libros de caballerías: Tirante el Blanco (1511) frente a las críticas de Juan de Molina, Luis Vives y Jerónimo Sempere», Historias fingidas, 7, pp. 61-127.

y Josep IzQuierdo (1997), «Tirant le Blanc: bibliographie essentielle», en Jean Marie Barberà (ed.), Actes del Col.loqui International Tirant lo Blanc [ «l'albor de la novel.la moderna europea». Ais de Provença, 21-22 d'octubre de 1994]. Estudis crítics sobre «Tirant lo Blanc»i el seu context, Centre Aixois de Recherches Hispaniques-Institut Interuniversitari de Filologia Valenciana, Publicacions de l'Abadia de Montserrat, pp. 477-484.

Bensoussan, Mathilde (1997), «Tirant le Blanc au XVIIİ̀ siècle: l'adaptation française du comte de Caylus», en Jean Marie Barberà (ed.), Actes del Col.loqui International Tirant lo Blanc [ «l'albor de la novel.la moderna europea $\gg$. Ais de Provença, 21-22 d'octubre de 1994]. Estudis crítics sobre «Tirant lo Blanc» i el seu context, Centre Aixois de Recherches Hispaniques-Institut Interuniversitari de Filologia Valenciana, Publicacions de l'Abadia de Montserrat, pp. 469-475.

Bougainville, Jean-Pierre (1756), «Éloge de M. Fréret». en Histoire de l'Académie des Inscriptions et Belles-Lettres. Avec les Mémoires de Littérature tirée des Registres de cette Académie depuis l'année MDCCXLIX jusques \& compris l'année MDCCLI, Tome Vingt-troisième, París, De 1'Imprimerie Royale, pp. 314-337.

Calvo Rigual, Cesáreo (1991), «Estudi bibliogràfic de les edicions de la traducció francesa de Tirant lo Blanc», en Antoni Ferrando Francés i Albert Guillem Hauf Valls (eds.), Miscel.lània Joan Fuster: estudis de llengua i literatura, vol. III, Valencia-Barcelona, Universitat de València, Publicaciones de l'Abadia de Montserrat, pp. 179-194

49. Achille-Joseph de Robert Marqués de Lignerac que fue Conde de Caylus (1765) y Duque de Caylus (1770). 
CaYlus [Anne-Claude-Philippe de Tubières de Grimoard de Pestels de Lévis, Comte de Caylus], (1752-1767), Recueil d'Antiquités égyptiennes, étrusques, grecques, romaines et gauloises, París, 7 vols.

(1787a), Euvres badines complettes, du Comte de Caylus, avec figures. Première partie. Tome premier. A Amsterdam \& se trouve à Paris, Chez Visse. Incluye: «Préface de l'éditeur» (pp. 5-16); «Avertissement de l'éditeur» (pp. 21-24); «Avertissement du traducteur imprimé en tête de l'édition de 1740» (pp. 25-48) e «Histoire du vaillant chevalier Tiran Le Blanc» (pp. 49-378). [atribuido a] (1787b), «Projet d'un voyage en Espagne. Pour constater un fait important de l'histoire du chevalier don Quichotte. Lu dans l'Académie de Troyes, le 10 Mai 1744. Par M *** 1'un des sept», en Euvres badines complettes, du Comte de Caylus, avec figures. Cette partie contient plusieurs historiettes \& ouvrages critiques \& facétieux qui lui ont été attribués. Tome douzième. A Amsterdam \& se trouve à Paris, Chez Visse, pp. 95-110.

Courcelles, [Jean-Baptiste-Pierre] [M. le Chevalier de] (1824), «Fragment sur la maison de Tubières [in De Bonne]», en Histoire généalogique et héraldique des pairs de France, des grands dignitaires de la couronne, des principales familles nobles du royaume, et des maisons princières de l'Europe, précédée de la généalogie de la maison de France. Par M. le Chevalier de Courcelles, Ancien Magistrat, l'un des Continuateurs de l'Art de vérifier les Dates. Tome quatrième, París, Chez l'Auteur, Chez Arthus Bertrand, pp. 10-23.

De Ceballos-Escalera Gila, Vizconde de Ayala, Alfonso (en línea), «Thubières de Grimoard, Claude-Abraham», en Diccionario Biográfico Español, Real Academia de la Historia (consultado el 17 de agosto del 2021). <https://dbe.rah.es/biografias/70087/claude-abraham-thubieres-de-grimoard>

Felipo Orts, Amparo (2013), «El canónigo don José de Castellví y Coloma (1677-1739): entre el ministerio eclesiástico y la defensa del patrimonio familiar», en Emilio Callado Estela (ed.), La catedral ilustrada: Iglesia, sociedad y cultura en la Valencia del siglo XVIII, Valencia, Institució Alfons el Magnànim, I, pp. 127-154.

FréRET, Nicolas (1753), «Éloge de M. l'abbé Souchay» in Histoire de l'Académie royale des inscriptions et belles-lettres, avec les Mémoires de littérature tirés des registres de cette académie, depuis l'année MDCCXLIV jusques \& compris l'année MDCCXLVI. Tome dix-huitième, París, Imprimerie royale, XVIII, pp. 458-462.

García Mercadal, José (1999), Viajes de extranjeros por España y Portugal desde los tiempos más remotos hasta comienzos del siglo XX. Recopilación, traducción, introducción al siglo XVIII y notas, Madrid, Junta de Castilla y León, vol. IV.

Gougeaud-Arnaudeau, Simone (2010), Le Comte de Caylus (1692-1765): pour l'amour des arts, París, L'Harmattan Historique.

Grell, Chantal y Catherine Volpilhac-Auger (eds.) (1994), Nicolas Fréret, légende et vérité. Colloque des 18 et 19 octobre 1991, Clermont-Ferrand, Oxford, Voltaire Foundation.

Le BEAU, Charles (1767), «Éloge historique de M. le Comte de Caylus lu à la rentrée publique de 1'Académie Royale des Inscriptions \& Belles-Lettres le mardi 8 avril 1766 par M le Beau, Secrétaire perpétuel de la même Académie», en Caylus, Recueil d'Antiquités égyptiennes, étrusques, grecques et romaines. Supplément, Tome septième, París, Chez N. M. Tilliard, pp. I-XxiII.

Leroy, Pierre E. y Marcel Loyau (eds.) (1998), Mme de Maintenon, Mme de Caylus et Mme de Dangeau. L'estime et la tendresse. Correspondances intimes réunies et présentées par--, préface de Marc Fumaroli, París, Albin Michel. 
Martines, Vicent (1993), «El Tirant lo Blanch a Itàlia. "In Spagna é reputato come qui il Decamerone di Giovanni Boccaccio"», en Rafael Alemany, Antoni Ferrando i Lluís B. Messeguer (eds.), Actes del novè Col-loqui Internacional de Llengua i Literatura Catalanes. Alacant / Elx, 9-14 setembre de 1991, Barcelona, Publicacions de l'Abadia de Montserrat, Universitat d'Alacant, Universitat Jaume I, Universitat de València, vol. II, pp. 173-182.

(2006), «Lectors i traduccions per a Tirant lo Blanch: Quixot, Renaixement, Barroc i Illustració per a la recepció de Tirant lo Blanch a Europa», en Enric Balaguer (ed.), El Quixot i els Clàssics Valencians, Alacant, Universitat d'Alacant, pp. 81-116.

Martínez Aloy, José (1908), «Inscripciones saguntinas revisadas en 1753», Boletín de la Real Academia de la Historia, LII, cuad. III, pp. 169-174.

[MArtorell, Joanot], [1740], Histoire du vaillant chevalier Tiran le Blanc. Traduite de l'espagnol. Tome premier, A Amsterdam, Chez Westein \& Smith. [Avertissement (pp. III-XxxII); Histoire (pp. 1-336)].

[__ ], (1783), «Histoire du vaillant chevalier Tiran le Blanc, traduite de l'espagnol par le Comte de Caylus», en Bibliothèque universelle des romans: ouvrage périodique, dans lequel on donne l'analyse raisonnée des Romans anciens \& modernes, François, ou traduits dans notre Langue; avec des Anecdotes \& des Notices historiques \& critiques concernant les Auteurs ou leurs Ouvrages : ainsi que les Mours, les Usages du temps, les circonstances particulières \& relatives \& les Personnages connus, déguisés ou emblématiques. octobre 1783, 2è volume, Paris, Au Bureau, rue Neuve Sainte-Catherine \& Chez Demonville, pp. 3-68.

(1997), Tirant le Blanc, traduction et adaptation en français par le Comte de Caylus, ed.J. M. Barberà, précédé de «Tirant le Blanc: les mots comme actions» par M. Vargas Llosa, et «Un gentilhomme universel: A.C. de Thubières, Comte de Caylus» par M. Fumaroli, París, Gallimard.

MAs, Pasqual y Javier Vellón (eds.) (2017), Juan Basilio de Castellví y Coloma, conde de Cervellón. Poesía y epistolario, Valencia, PUV.

MaYans y Siscar, Gregorio (2006), Vida de Cervantes, estudio introductorio de Antonio Mestre, Valencia, Consell Valencia de Cultura.

Mestre Sanchis, Antonio (1976), «Interès per la llengua "llemosina” entre els amics estrangers de Mayans i Siscar», en Primer Congreso de Historia del País Valenciano, celebrado en Valencia del 14 al 18 de abril de 1971, Volumen 3: Edad Moderna, Valencia, Universidad de Valencia, pp. 609-620.

(2003), «El teatro del Siglo de Oro español en la correspondencia entre Voltaire y Mayans», en su Apología y crítica de España en el siglo XVIII, Madrid, Marcial Pons, pp. 267-288.

(2006), «Estudio introductorio», en Gregorio Mayans y Siscar, Vida de Cervantes, Valencia, Consell Valencia de Cultura, pp. vi-LII.

(2012), «La frustrada relación de Mayans con el Cardenal Fleury», en David Bernabé y Armando Alberola (eds.), Magistro et amico. Diez estudios en homenaje al profesor Enrique Giménez López, Alicante, Publicaciones de la Universidad de Alicante, pp. 45-64.

Minervini, Vicenzo (1993), «La prima analisi critica del Tirant: l'Avertissement di Nicolas Fréret», en Rafael Alemany, Antoni Ferrando i Lluís B. Messeguer (eds.), Actes del novè Col.loqui Internacional de Llengua i Literatura Catalanes. Alacant / Elx, 9-14 setembre de 1991, Barcelona, Publicacions de l'Abadia de Montserrat - Universitat d'Alacant - Universitat Jaume I - Universitat de Valencia, vol. II, pp. 183-190.

Montoya Uriarte, Huayta (2020), Caylus, un pionero de la arqueología del siglo XVIII. España y América en su «Recueil d'antiquités» (1752-1767), Trabajo Final de Grado de Arqueología, 
dirigido por Margarita Díaz-Andreu, Barcelona, Universidad de Barcelona. <http://diposit. ub.edu/dspace/handle/2445/172201>

Nouveau Dictionnaire historique portatif, ou histoire abrégée de tous les hommes qui se sont fait un nom par des talens, des vertus, des forfais, des erreurs, \& \& depuis le commencement du monde jusqu'à nos jours: ouvrage dans lequel on expose sans flatterie do sans amertume, ce que les écrivains les plus impartiaux ont pensé sur le génie, le caractère \& les mours des hommes célèbres dans tous les genres; avec des tables chronologiques pour réduire en corps d'histoire les articles répandus dans le Dictionnaire. Par une Société de Gens de Lettres. Nouvelle édition revue, corrigée \& augmentée. Amsterdam, Chez Marc-Michel Rey Libraire, 1769, t. I, pp. 458-459 (Caylus) y t. II. pp. 177 (Fréret).

Pasumot, M. (1813 [1766]), «Éloge historique de M. Anne-Claude-Philippe de Tubière, de Grimoard, de Pestels de Levy, Comte de Caylus, Marquis d'Esternay, Baron de Bransac, Conseiller d'honneur au Parlement de Toulouse, et Membre de plusieurs Académies et Sociétés savantes [5 juin 1766] », en Dissertations et mémoires sur différents sujets d'Antiquité et d'histoire, mis en ordre et publiés d'après les manuscrits de feu M. Pasumot, ingénieur-géographe du Roi, par C. M. Grivaud, membre de plusieurs Sociétés savantes, París, s. e., 1810 à 1813, pp. 15-27.

Payen, Jean-François (1848), Histoire sérieuse d'une Académie qui ne l'était pas, París, Imprimerie de Guiraudet et Jouaust. [Se publicó originalmente como « Recherches sur les Mémoires de l'Académie de Troyes en Champagne», en la Bibliographie Universelle: Journal du Libraire et de l'Amateur de Livres, París, 1848].

Peeters, Kris (2004), «Bibliographie critique du Comte de Caylus », en Nicholas Cronk y Kris Peeters (eds.), Le Comte de Caylus. Les Arts et les Lettres. Actes du colloque international Université d'Anvers (UFSIA) et Voltaire Foundation, Oxford, 26-27 mai 2000, Ámsterdam-Nueva York, Rodopi, pp. 277-363.

Peset LLorCa, Vicent (1975), Gregori Mayans i la cultura de la il.lustració, prologo de Antoni Mestre, Barcelona, Curial - Valencia, Tres i Quatre.

RauniÉ, Émile (ed.) (1881), Souvenirs et correspondance de Mme de Caylus. Première édition complète publiée avec une annotation historique, biographique et littéraire et un index analytique par --, París, G. Charpentier.

Rius, Leopoldo (1895-1899), Bibliografía crítica de las obras de Miguel de Cervantes Saavedra, Madrid, Librería de M. Murillo, 2 vols.

Rocheblave, Samuel (1889), Essai sur le Comte de Caylus: l'homme, l'artiste, l'antiquaire, París, Hachette.

Rodríguez, Josep (1747), Biblioteca valentina. Compuesta por el M. R.P. M. Fr. Josef Rodríguez, Ministro del Real Convento del Remedio de Valencia, Cronista General del Orden de la SS Trinidad en la Provincia de Aragón. Por su muerte, interrumpida su impresión. Aora continuada, y aumentada con el Prólogo y Originales del mismo Autor. Añadidas algunas enmiendas y correcciones, como las dexó el autor entre sus originales, con que se mejoran muchos lugares de su Obra. Juntase la continuación de la misma obra, hecha por el MRPM Fr. Ignacio Savalls, del mismo Orden, Provincial, y nombrado Cronista de la Provincia de Aragón. Dedicada a la M.I. Ciudad de Valencia, Valencia, Joseph Thomas Lucas.

Simón, Renée (1961), Nicolas Fréret académicien (1688-1749), Liverpool, Voltaire Foundation Liverpool University Press.

Vernière, Paul (1978), «Une lettre inédite du comte de Caylus», en Mélanges de littérature du Moyen Age au XXe siècle offerts à Mademoiselle Jeanne Lods, París, École Normale Supérieure de Jeunes Filles, vol. II, pp. 742-744. 
Vila, Josep Maria (ed.) (1997), Partinuples. Précis sur la romance catalane; Histoire du vaillant chevalier Tiran le Blanc (facsímils d'unes desconegudes impressions franceses de 1779 i 1783), Girona, Diputació de Girona - Patronat Francesc Eiximenis.

WALCKenaer, Charles A. (1850), Rapport fait à l'Académie des Inscriptions et Belles-Lettres au sujet des manuscrits inédits de Fréret, París Imprimerie Nationale.

Ximeno, Vicente (1747-1749), Escritores del Reyno de Valencia, chronologicamente ordenados desde el año MCCXXXVIII de la Christiana conquista de la misma ciudad, hasta el de MDCXLVII, Valencia, Josep Estevan Dolz, 2 vols. 